\title{
Impact of Confinement on Flowfield of Swirl Flow Burners
}

\author{
Ahmed E.E. Khalil, Jonathan M. Brooks, and Ashwani K. Gupta* \\ Department of Mechanical Engineering, \\ University of Maryland, College Park, MD 20742, USA
}

Abstract

Swirlers are commonly used in gas turbine combustors as they provide recirculation zones for enhanced flame stability. Swirl provides hot gas recirculation zone at front end of the combustor for enhanced mixing between hot reactive species and the freshly introduced mixture. In this paper, the impact of confinement on a swirl assisted combustion was investigated with focus on the flowfield under unconfined and confined conditions. The features of the flowfield were characterized under both isothermal and reacting conditions. Experimental results showed that for the unconfined cases, the flowfield exhibited the traditional central toroidal recirculation zone. Upon confinement, this zone shortened and also widened with increased velocity fluctuations across the combustor. Increase in the

15 Reynolds number further enhanced the recirculation zone and increased the velocity magnitudes and turbulence. For reacting conditions, minimal recirculation was noticed for the unconfined flame. The recirculation zone was significantly enlarged upon confinement (compared to the non-reacting case) and with increase in Reynolds number. In general, the fluctuating velocity was found to be higher in the confined case compared to the unconfined case, and even higher at increased Reynolds number.

Keywords: Swirl flames, Particle Image Velocimetry (PIV), Flame Confinement, Gas turbine combustion.

\footnotetext{
* Corresponding author: Tel.: +1 301405 5276; Fax: +1 3013149477.

E-mail address: akgupta@umd.edu (A. K. Gupta).
} 


\section{Introduction}

Gas turbine (both stationary and for aviation) widely uses swirling flow for controlled mixing of air, fuel and reactive species with the goal to enhance flame stability and control pollutants emission. These significant benefits along with swirl deployment in other engineering

5 applications have stimulated many studies, both experimental and numerical, to characterize swirling flow under different conditions (confinement, aspect ratio, operating conditions, etc.).

Swirling flows have been commonly used for furnaces and gas turbines among others. Characteristics of swirling flow generated by simple swirlers have been reviewed and investigated by multiple researchers [1-3]. These reviews have provided different methods of

10 generating swirl in the system, the parameters that affect the size of the recirculation zone, and flow structure produced by different swirlers. Most of the discussed results were obtained using intrusive instrumentation and therefore the true detailed flow structure was not obtained.

Multiple research groups performed subsequent studies using non-intrusive diagnostics [410]. Cheen et al [4] investigated confined and unconfined annular swirling jet flows with

15 different Reynolds' number (Re 60-6000) and Swirl numbers (with S of 0-0.6). They classified the recirculation zone into seven different categories based on Re and S. They concluded that the behavior of these seven categories were the same for both confined and unconfined configuration with the exception of one regime (called attachment regime) [4]. Mongia et al has performed an extensive review covering research performed on swirl cup burners (at GE, University of

20 Cincinnati, and the University of California Irvine), and provided a benchmark Laser Doppler Velocimetry (LDV) data for modeling, and outlined some empirical design rules [5]. In one of the subsequent publication, Cai et al outlined the impact of confinement on the flowfield, where smaller confinement has the strongest impact on the flowfield, while larger confinement looked 
similar to that of the unconfined case [6]. It is worth noting that these measurements were performed under non-reacting conditions. Archer et al [7] outlined the role of confinement under fuel lean combustion using a double concentric swirl burner. They concluded that confinement decreases both the central recirculation zone and strength and increases the turbulence level. In

5 addition, confinement decreased axial velocity magnitude under non-reacting condition [7]. Fu et al [8] also studied a counter rotating radial swirler under non-reacting condition. They outlined the clear impact of confinement on mean and turbulent flowfield, wherein their results showed recirculation zone for the confined case was almost twice that of the unconfined case, which was contradictory to what outlined by Archer et al [7], however, this difference can be attributed to 10 the much higher Re number utilized by Fu et al ( 60000 [8] vs. 8000 [7]), as well as the different swirl geometry.

More recently, low swirl burners have been proposed in contrast to high swirl burners due to their benefits in terms of reduced emissions $[9,10]$, stabilization of planar flames without heat losses or boundary effect [11], and low pressure drop. In another study, Cheng et al investigated

15 the flowfield of low swirl injector [12]. They outlined the difference between unconfined and confined cases under reacting and non-reacting conditions with methane and hydrogen as the fuel with confinement ratios of 3 and 2.44:1. They demonstrated that enclosure increases the central recirculation zone under non-reacting conditions. On the other hand, for methane flames, enclosure had minimal effect at the 3:1 confinement ratio; however, the smaller confinement did 20 not generate central flow recirculation [12]. Other researchers examined the flowfield, temperatures, and species distribution within swirl flames [13-16].

From the previous summary, one can see that confinement has an effect for some cases but not others, depending on Reynolds' number, swirl geometry, and whether the experiments were 
performed under isothermal (non-reacting) or combustion (reacting) conditions. In this paper, the impact of confinement on a swirl burner flowfield is examined with focus on low-intermediate swirl configuration that will help resolve some of the discrepancies found in the literature on general flowfield from different swirl burners and to quantify the role of confinement and

5 combustion on the changes in flow behavior. It is noteworthy that the literature mainly discuses confinements that are larger compared to the one discussed here as explained in the experimental setup. Another goal here is to characterize the swirl burner for further numerical and experimental studies under swirl and distributed combustion conditions [17]. For these purposes, experiments are performed under both non-reacting and reacting conditions to outline the impact

10 of heat release on the flowfield. The flowfield measurements have been further analyzed to obtain turbulence characteristics, such as, velocity fluctuations and turbulence kinetic energy. These quantities play an important role in characterizing the flowfield as well as the turbulent Reynolds' number calculation.

\section{2. Experimental Facility}

\subsection{Experimental Setup}

The experiments were performed using a swirl burner under different configurations. Details of the swirl burner can be found elsewhere [18]. For all the cases reported here, methane was used as the fuel. A laminar flow controller with an accuracy of $\pm 0.8 \%$ of the reading and $\pm 0.2 \%$ of full scale was used to

20 control the air flow rates, leading to an overall accuracy of about $1.5 \%$ of the reading. Methane and seeding air flow rates were controlled through gravimetric flow controllers with an accuracy of $1.5 \%$ of full scale. Fuel was injected at the center of the swirler in a non-premixed configuration. Figure 1 shows the flow configuration of the swirl while Fig. 2 shows a schematic diagram of the facility and the diagnostic tools used. For the swirler, the Swirl number (S) can be calculated using the equation 
$\mathrm{S}=2 / 3\left[\left(1-\left(\mathrm{d}_{\mathrm{h}} / \mathrm{d}\right)^{\wedge} 3\right) /\left(1-\left(\mathrm{d}_{\mathrm{h}} / \mathrm{d}\right)^{\wedge} 2\right)\right] \tan \Phi$, where $\mathrm{d}$ is the swirler diameter, $\mathrm{d}_{\mathrm{h}}$ is the swirl hub diameter, $\Phi$ is the swirl angle. For the shown configuration, $\mathrm{d}_{\mathrm{h}} / \mathrm{d}=0.5$, and $\Phi=45$, yielding a swirl number $S=0.77$. If one considers the conical shape after the swirler where the hub diameter goes to zero, the approximation of Lilley [2] can be followed, where swirl number $S$ can be approximated to $S=2 / 3 \tan \Phi$, $\Phi$ is the swirl

5 angle. This yields a swirl number $S=0.66$. The swirl burner was confined using a quartz cylinder with a diameter ratio $\left(D_{q} / D_{b}\right)$ of 1.7 , where $D_{q}$ is the quartz diameter and $D_{b}$ is the burner diameter, leading to an area ratio of 2.9. This is significantly smaller than values reported in the literature (4 by Archer et al [7] and Fu et al [8], 6 and 9.9 by Cheng et al [12], and 12.25 by Nogenmyr et al [19]). It is to be noted that both the confinement ratio and swirl configuration used here are different than those cited in the above 10 investigations.

\subsection{Particle Image Velocimetry}

Particle image velocimetry (PIV) system was used here to obtain the flowfield. The camera was located at a distance of $0.5 \mathrm{~m}$ away from the laser plane. The camera view covered an area

15 of about $7 \mathrm{~cm} \times 6 \mathrm{~cm}$. Portion of the air supplied to the combustor was diverted to a fluidized bed seeder, where the seeding particles were picked up by the air and then combined with the main airflow line, see Fig. 2. The portion of air diverted was about $10 \%$ and the flow rates of the main air and seeding air were controlled to reach the desired total air flow for all the experimental conditions examined. The seeding particles used were Alumina Oxide with a nominal particle diameter of $2 \mathrm{um}$. The laser sheet beam had a thickness of about $1 \mathrm{~mm}$ and was used to illuminate the seed particles in the flow. Table 1 summarizes the different parameters used in the PIV system.

For data processing, PIVLab was used [20]. For each data set, four passes were performed with interrogation window size of $48,36,24$, and 12 pixels with $50 \%$ overlap. High reflection 
regions and noise were handled through masks to eliminate erroneous vectors resulting from the high signals, leading to areas of "no vectors" in the velocity field. A minimum of 300 pairs were obtained for each case to obtain statistical information on the flowfield. The number of image pairs were determined based on the point where further increase in the number of pairs did not

5 yield significant change in the measured quantities $(<5 \%)$, see Fig. 3. The PIVLab output was further processed in Matlab to obtain mean and fluctuating velocities and other relevant quantities on the flowfield.

\section{Experimental Conditions}

The experimental investigations reported here were focused on obtaining the velocity field

10 and turbulence quantities. The first experimental condition, representing a baseline case, was an unconfined swirling flame configuration. The second condition was a confined swirl case that provided the impact of confinement on the combustor behavior. These two cases were examined under reacting and non-reacting conditions. The third case represented a confined flame with higher air flow rate (lower equivalence ratio) to examine the impact of increased Reynolds

15 number on flowfield. Figure 4 shows the flame obtained for confined and unconfined cases, while table 2 summarizes the operating conditions for each of the experimental cases.

\section{Results and Discussion}

\subsection{Non-reacting flow field}

20 The flowfield under non-reacting conditions was first obtained. This included unconfined and confined configurations. For the confinement, the confinement diameter to the swirler hub diameter ratio was 1.7 leading to area ratio $\sim 2.9$. Figure 5 shows the velocity vectors for cases 1 3 along with the mean velocity value, where the white band marks the recirculation zone. The 
streamlines are also shown on the figure to outline the flow behavior. The white vertical zones mark areas where the noise was too high to obtain meaningful data. One can notice that the recirculation zone was significantly shortened in length and widened upon confinement. For the unconfined case, the central recirculation zone reached a height of $0.035 \mathrm{~m}$ and with a maximum

5 radius of $0.005 \mathrm{~m}$. Upon confinement, this height (or length) was decreased to $0.02 \mathrm{~m}$ while the radius increased to approximately $0.007 \mathrm{~m}$. In addition, the recirculation zone in the confined case further strengthened downstream of the burner, near the top, to extended in the entire length of the combustor. Also, an outer recirculation zone is evident on the right near to the wall of the confinement. Increase in the velocity, (case 3), strengthened the recirculation (notice the

10 different scale), with the presence of strengthened recirculation zone further downstream of the burner (as compared to that immediately downstream at the swirler exit). This phenomenon was not noticed with the reduced flow rate, outlining the impact of increased Reynolds number on the flow behavior. In addition, the increased Reynolds number increased the magnitude of the outer recirculation zone. As for the inlet jet, confinement led to the jet moving radially outwards with

15 less axial penetration as compared to the unconfined case. These results support the findings of Archer et al [7]. On the other hand, increasing Reynolds number led to more radial dispersion of the inlet jet. The streamlines for the different cases show the impact of confinement on recirculation (width and magnitude).

The velocity fluctuations for the same cases were also obtained and are shown in Fig 6. For 20 the unconfined case, most of the velocity fluctuations (axial velocity) was limited to the inlet region and the central recirculation zone boundary. As the swirler was confined, the turbulence significantly increased all over (with values around $2.5 \mathrm{~m} / \mathrm{s}$ vs. $1.6 \mathrm{~m} / \mathrm{s}$ for the unconfined case). In addition, fluctuations were noticed at the outer recirculation zone. Also fluctuations were 
noticed downstream of the central recirculation. As Reynolds number was increased, the fluctuating velocity increased significantly to reach values of $3.5-4 \mathrm{~m} / \mathrm{s}$ while the additional recirculation zone downstream had values of $4.5 \mathrm{~m} / \mathrm{s}$ (notice the different scale). It is noteworthy that this downstream zone showed higher recirculation (higher negative velocities) as compared

5 to the central recirculation zone shown in Fig 5. Comparing both the confined cases, one can see that for case two, strong fluctuations exist; however, the velocity fluctuations are not high enough to cause negative velocities and recirculation as compared to the higher Reynolds number case, case 3.

The 2-D turbulent kinetic energy can be used to show the energy distribution within the

10 flowfield and how it is dissipated under different conditions. Turbulent kinetic energy (TKE) is calculated using the formula $\mathrm{TKE}=1 / 2 * \operatorname{sqrt}\left(\mathrm{urms}^{\wedge} 2+\mathrm{vrms}^{\wedge} 2\right)$, and the results are shown in Fig. 7. From the figure, once can see that confinement increases the kinetic energy values to almost double of that obtained without confinement. In addition, for the increased Reynolds number case, the central recirculation zone downstream exhibited the highest TKE. It is noteworthy that

15 the TKE calculated here is based on only two of the three velocity components.

The non-reacting results are similar to the results of Archer it al [7] where the recirculation zone was shortened. However, as stated earlier, the recirculation zone is widened along with an overall increase in strength. These results agree with the findings of Fu et al [8] and Cheng et al [12].

\subsection{Reacting flow field}

The experiments were performed under reacting flow conditions. The results obtained are shown in Fig. 8. Vertical white lines represent masks used to eliminate erroneous vectors at these 
locations due to high noise and laser reflections at these locations. For the unconfined case, one can notice that there is lack of recirculation zone, aside from a very small area at the center; there was no reverse flow, as validated from the observed streamlines only moving up. Another thing to notice is the increase of velocity; this is attributed to the heat release and expansion of gases as

5 their density significantly drops ( $1 / 3-1 / 4$ of its value as that at room temperature). As the flow is confined, a large recirculation zone is shown in the center, which spreads wider downstream. The recirculation zone is surrounded by a white band (for velocities $\sim 0 \mathrm{~m} / \mathrm{s}$ ) for illustration. Similar to the non-reacting case, an outer recirculation zone is also evident. For both positive and negative velocities, the magnitude was almost double of that demonstrated in the non-reacting case. As the flow rate was increased (case 6), as well as Reynolds number, the recirculation zone grew even wider (seen through comparison of middle figures with bottom figures). The negative velocity magnitude was about -2.5 to $-3 \mathrm{~m} / \mathrm{s}$ as compared to -1.5 to $2 \mathrm{~m} / \mathrm{s}$ in the lower Reynolds number case (case 5). Also, the positive velocity increased as the total flow increased. Comparing the streamlines for cased 5 and 6 , one can see that they are similar, with the

15 exception of case 6 showing a wider "down" movement as the recirculation zone is larger. For all the discussed cases, the white band marks the recirculation zone. Each of the cases has its own scale for better representation of gradients.

The velocity fluctuations for the same cases were also obtained and are shown in Fig 9. For the unconfined case, most of the velocity fluctuations (axial velocity) were limited to the inlet 20 region with values around $3 \mathrm{~m} / \mathrm{s}$. As the swirler was confined, the turbulence significantly increased all over (with values of around $4 \mathrm{~m} / \mathrm{s}$ vs. $3 \mathrm{~m} / \mathrm{s}$ for the unconfined case at the entry region). As Reynolds number was increased, the fluctuating velocity increased significantly to reach values of 5-6 m/s around the entry region. The average for the unconfined case was about 2 
$\mathrm{m} / \mathrm{s}$, which increased to $3.25 \mathrm{~m} / \mathrm{s}$ upon confinement, and to $4.5 \mathrm{~m} / \mathrm{s}$ upon increasing the Reynolds number.

Similar to the non-reacting case, the 2-D turbulent kinetic energy was calculated and shown in Fig. 10. Similar to the non-reacting case, confinement increased the values of TKE (from $2.6 \mathrm{~m} / \mathrm{s}$

5 to $3 \mathrm{~m} / \mathrm{s}$ ). In addition, increasing the Reynolds number also increased the TKE to $4 \mathrm{~m} / \mathrm{s}$. The increased values under reacting conditions as compared to the non-reacting conditions are attributed to the energy release from combustion and the subsequent expansion of gases and increase in velocity.

The obtained results, showing a strong recirculation zone upon confinement for reacting flow

10 contradicts the findings of Cheng et al [12] wherein they did not observe central recirculation zones. On the contrary, the recirculation zone did not exist in the unconfined case, and upon confinement, a strong recirculation zone was evident that is contrary to the observation of Archer et al [7] where they reported a decrease in central recirculation size and strength upon confinement. However, the increase in turbulence agrees with their findings [7] to reveal the 15 importance of flow conditions and geometry on the presence of additional turbulence.

\section{Conclusions}

The flowfield of a low swirl burner was characterized under both isothermal and combustion conditions with focus on establishing the impact of confinement and flow behavior. The obtained

20 velocity fields and turbulence quantities were used to distinguish the behavior of the flow under these different cases (unconfined and confined, reacting and non-reacting, and increase in Reynolds number). The main findings can be summarized as follows: 
1. For the non-reacting flow, confinement decreased the length of the recirculation zone and increased its width. Also enhanced recirculation was noticed at the downstream locations of the burner that followed a low recirculation zone near to the swirler exit upon confinement.

2. Increase in Reynolds number under non-reacting conditions significantly increased the strength of the recirculation zone (both center and outer) with the presence of a secondary recirculation zone downstream of the burner inlet.

3. For reacting conditions, the recirculation zone for the unconfined case almost vanished as compared to the non-reacting one. Confinement restored the presence of this central recirculation zone, however; it was more widespread as compared to the non-reacting zone.

4. Similar to the non-reacting zone, increase in Reynolds number increased the recirculation with main entry jets being radially stretched outwards.

5. For both non-reacting and reacting conditions, confinement increased both the velocity fluctuations and the turbulent kinetic energy. The same trend was established with increase in Reynolds number.

\section{Acknowledgments}

This research was supported by ONR and is gratefully acknowledged.

\section{References}

[1] Syred, N., and Beer, J.M. Combustion in Swirling Flow: A Review. Combustion and Flame, 1974;23:143-201. 
[2] Lilley, D.G. Swirling Flows in Combustion: A Review. AIAA Journal 1977;15(8):10631078.

[3] Gupta, A.K, Lilley, D.G., and Syred, N. Swirl Flows. Abacus Press, Tunbrige Wells, England, 1984.

5 [4] Cheen, H.J., Chen, W.J., Jeng, W. Recirculation Zones of Unconfined and Confined Annular Swirling Jets. AIAA Journal 1996:34(3):572-579

[5] Mongia, H.C., AI-Roub, M., Danis, A., Elliott-Lewis, D., Jeng, S-M., Johnson, A., McDonell, V.G., Samuelsen, G.S., and Vise S. Swirl Cup Modeling. 37th AIAA/ASME/SAE/ASEE Joint Propulsion Conference \& Exhibit 8-11 July, 2001, Paper 10 \#AIAA-2001-3576

[6] Cai, J., Fu, Y., Elkady, A., Jeng, S., and Mongia, H. Swirl cup Modeling Part 4: Effect of Confinement on Flow Characteristics. 41st Aerospace Sciences Meeting and Exhibit 6-9 January 2003, Reno, Nevada Paper\#AIAA-2003-0486

[7] Archer, S., and Gupta A.K. The Role of Confinement on Flow Dynamics under Fuel 15 Lean Combustion. 2nd International Energy Conversion Engineering Conference, 16 - 19 August 2004, Providence, RI, Paper\#AIAA-2004-5617

[8] Fu, Y., Cai, J., Jeng S-M, and Mongia, H. Characteristics of the Swirling Flow Generated by a Counter-rotating Swirler. 43rd AIAA/ASME/SAE/ASEE Joint Propulsion Conference \& Exhibit 8 - 11 July 2007, Cincinnati, OH., Paper\#AIAA-2007-5690

20 [9] Johnson, M.R., Littlejohn, D., Nazeer, W.A., Smith, K. O., and Cheng R. K. comparison of the flowfields and emissions of high-swirl injectors and low-swirl injectors for lean premixed gas turbines. Proc. Of the Combust. Inst. 2005;30:2867-2874 
[10] Cheng, R.K., Yegian, D.T., Miyasato, M.M., Samuelsen, G.S., Benson, C.E., Pellizzari, R., Loftus, P. Scaling and Development of Low-Swirl Burners for Low-Emission Furnaces and Boilers. Proc. Of the Combust. Inst. 2000;28:1305-1313

[11] Plessing, T., Kortschik, C., Peters, N., Mansour, M.S., and Cheng R.K. Measurements of

5 the Turbulent Burning Velocity and the Structure of Premixed Flames on a Low-Swirl Burner. Proc. Of the Combust. Inst. 2000;28:359-366

[12] Cheng, R.K., and Littlejohn, D. Effects of Combustor Geometry on the Flowfields and Flame Properties of a Low-Swirl Injector. Proceedings of ASME Turbo Expo 2008: Power for Land, Sea and Air GT2008, June 9-13, 2008, Berlin, Germany, Paper\#GT2008-50504

10 [13] Weigand P, Meier W, Duan XR, Stricker W, and Aigner M. Investigations of Swirl Flames in a Gas Turbine Model Combustor. I. Flow Field, Structures, Temperature, and Species Distributions. Combustion and Flame, 2006;144:205-224.

[14] Stohr M, Sadanandan R, and Meier W. Experimental Study of Unsteady Flame Structures of an Oscillating Swirl Flame in a Gas Turbine Model Combustor. Proc. Combust. Inst., $15 \quad 2009 ; 32: 2925-2932$.

[15] Stopper U, Aigner M, Ax H, Meier W, Sadanandan R, Stohr M, and Bonaldo A. PIV, 2D-LIF and 1D-Raman Measurements of Flow Field, Composition and Temperature in Premixed Gas Turbine Flames. Exp. Thermal and Fluid Sci., 2010;34:396-403.

[16] Sadanandan R, Stohr M, and Meier W. Simultaneous OH-PLIF and PIV Measurements 20 in a Gas Turbine Model Combustor. Appl. Phys B., 2008;90:609-618.

[17] Khalil AEE, and Gupta AK. Impact of Internal Entrainment on High Intensity Distributed Combustion. J. Applied Energy, 2015;156:241-250. 
[18] Kim HS, Arghode VK, Linck MB, Gupta AK. Hydrogen Addition Effects in a Confined Swirl-Stabilized Methane-Air Flame. Int'1 J. Hydrogen Energy, 2009;34(2):1054-1062.

[19] Nogenmyr, K.J., Cao, H.J., Chan, C.K., and Cheng, R.K. Effects of Confinement on Premixed Turbulent Swirling Flames using Large Eddy Simulation. Combustion Theory and $5 \quad$ Modelling, 2013;17(6):1003-1019.

[20] Thielicke W, and Stamhuis EJ. PIVlab - Time-Resolved Digital Particle Image Velocimetry Tool for MATLAB (version: 1.4). http://dx.doi.org/10.6084/m9.figshare.1092508 


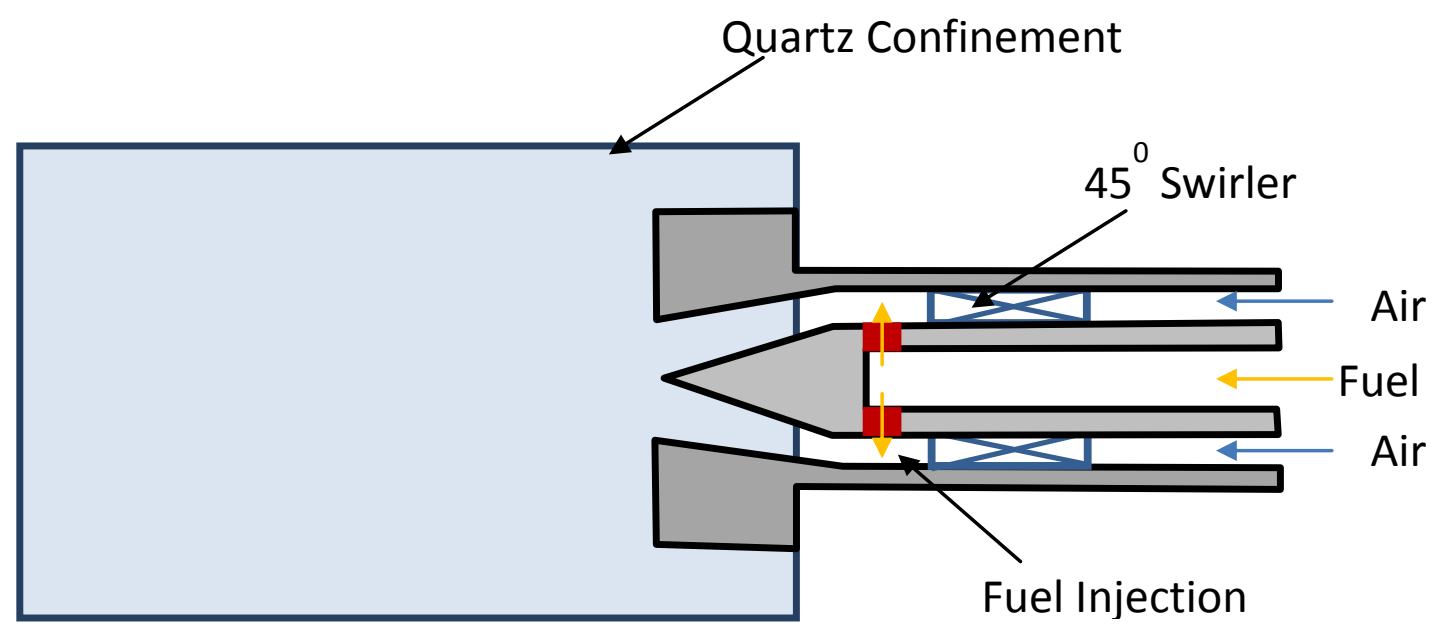

Figure 1. Schematic of the swirl configuration with $45^{\circ}$ swirl vane angle. 


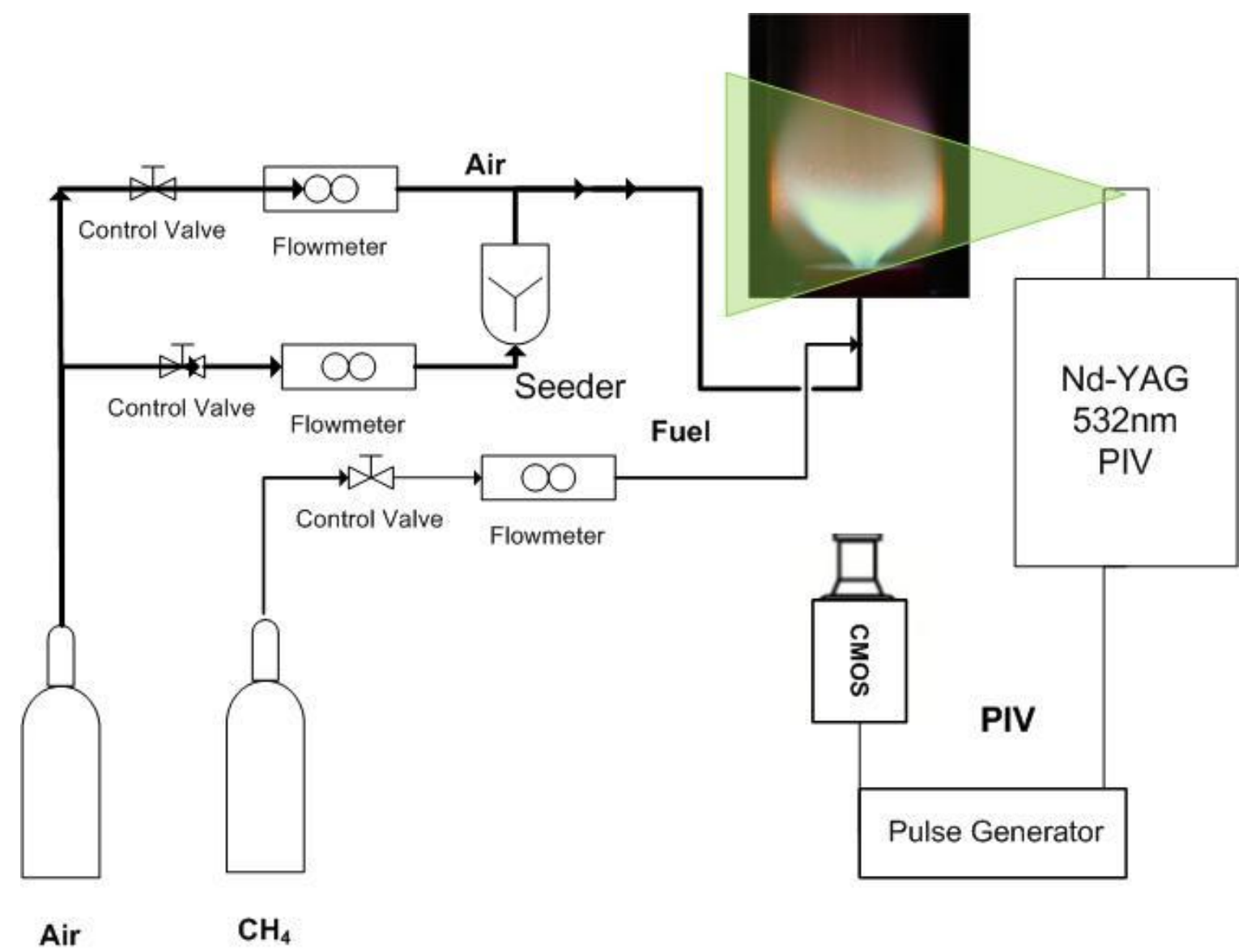

Figure 2. Schematic of the experiments including flow controls and laser diagnostics 


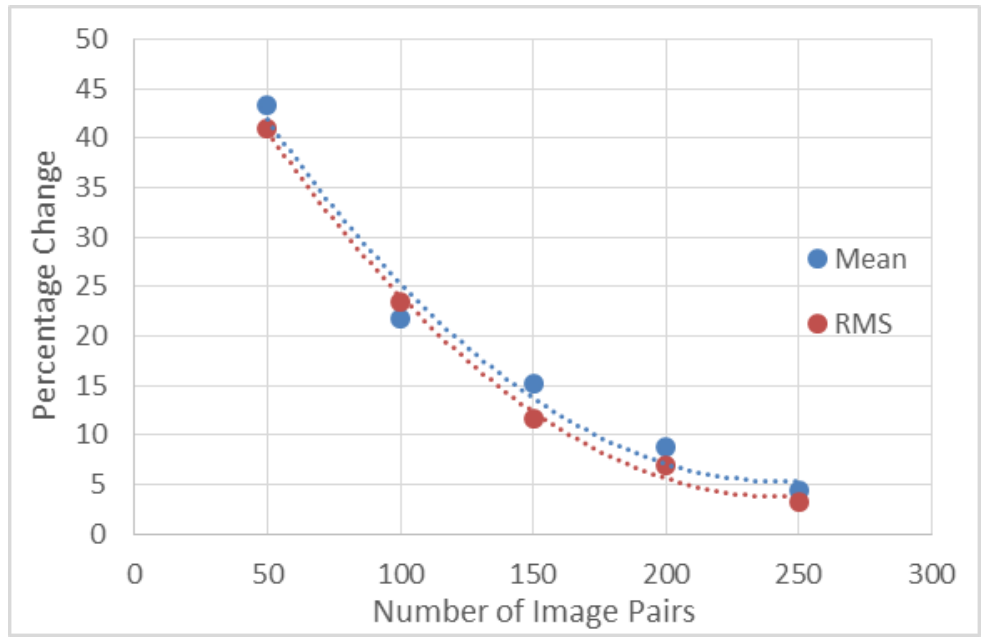

Figure 3. Percentage change in mean and fluctuating velocity vs. number of image pairs 


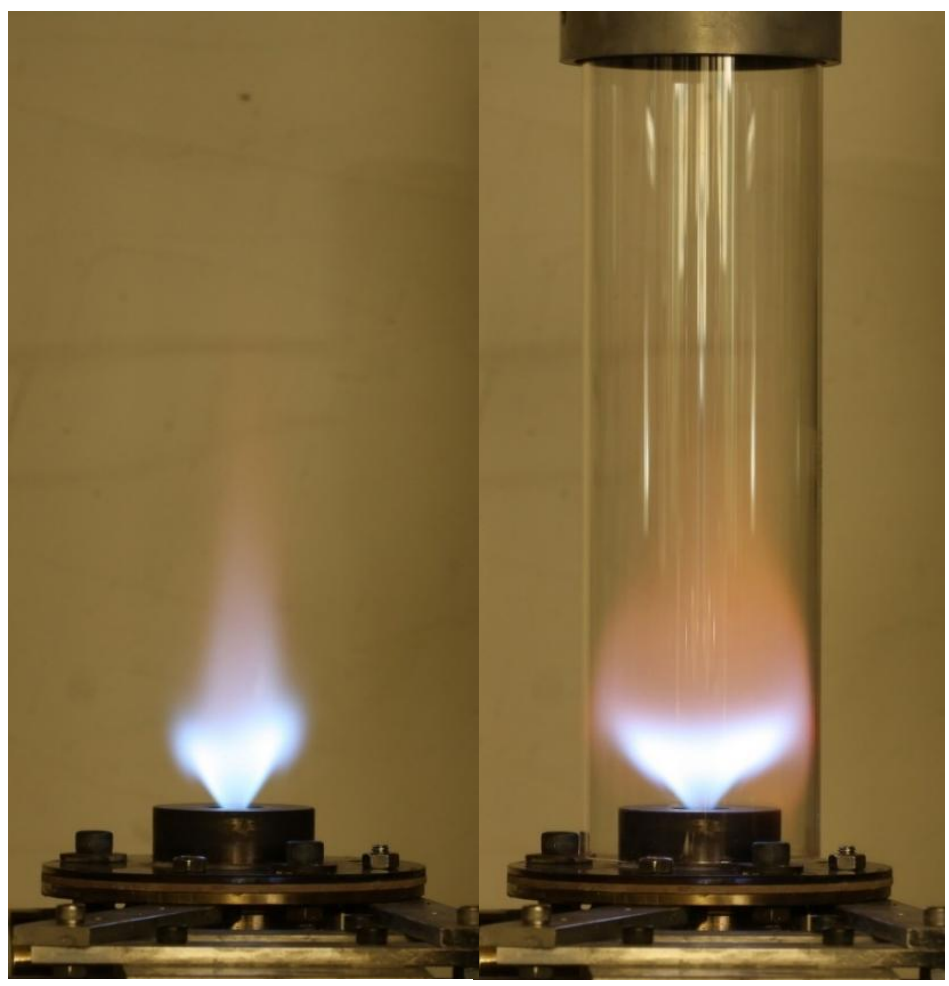

Figure 4. Swirl flame with swirl number $S=0.66$ : unconfined (left), confined (right). For the confined ace. I , $\mathbf{n}$ $-\Delta \mathbf{n}$ ./n . , 17 

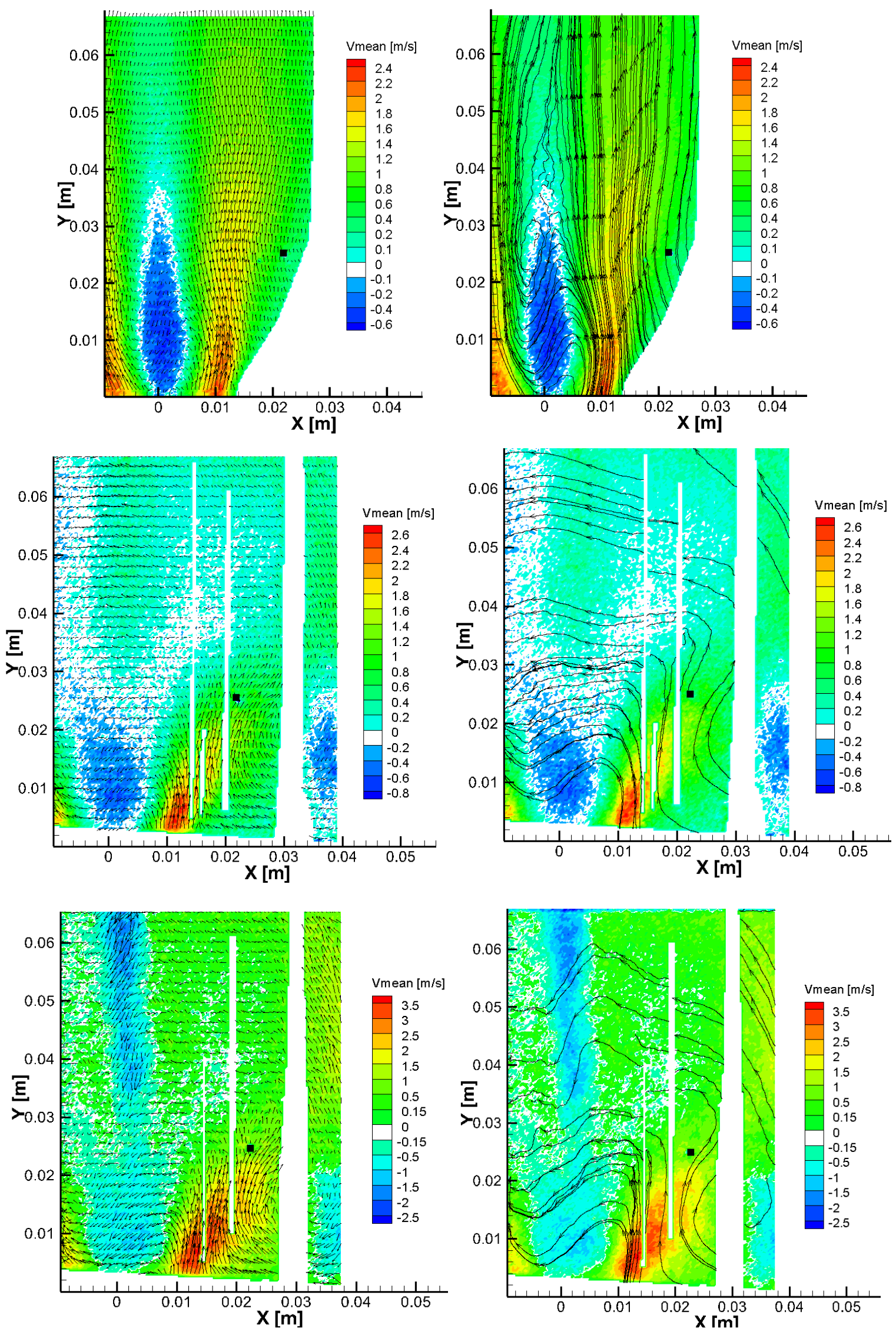

Figure 5. Velocity vectors and streamlines for unconfined case 1 (top), confined case 2 (middle), and confined increased Reynolds number case 3 (bottom) 

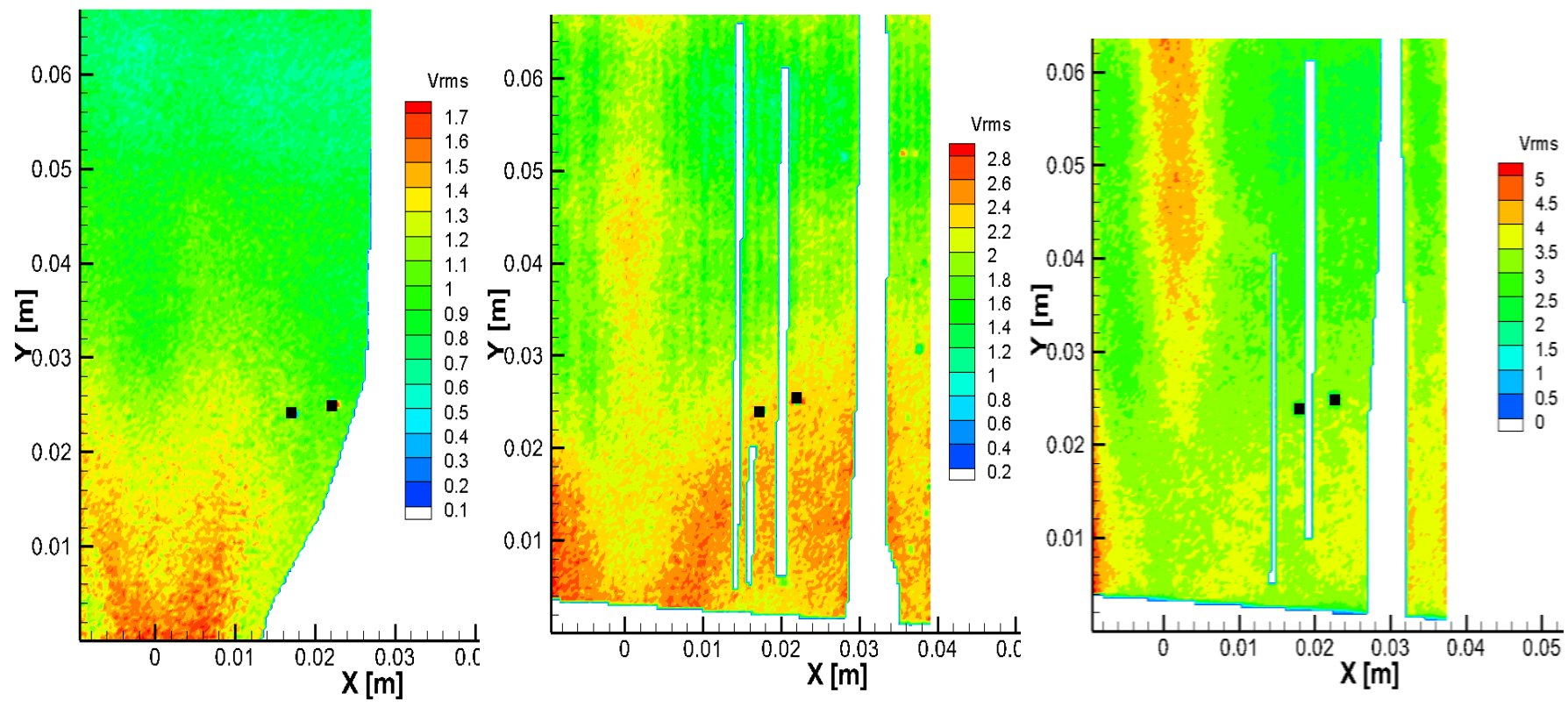

Figure 6. Fluctuating velocity for unconfined case 1 (left), confined case 2 (middle), and confined increased Reynolds number case 3 (right) 

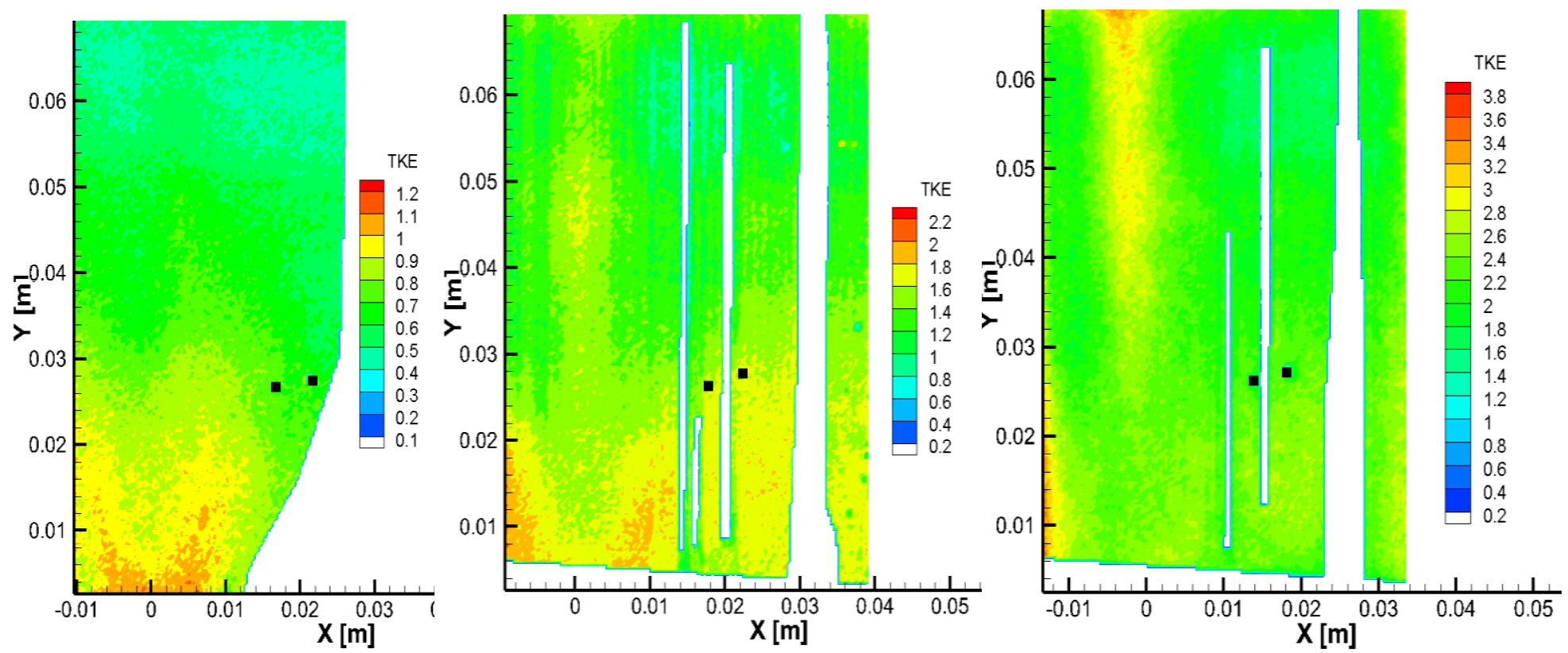

Figure 7. Turbulent kinetic energy (m/s) for unconfined case 1 (left), confined case 2 (middle), and confined increased Reynolds number case 3 (right) 

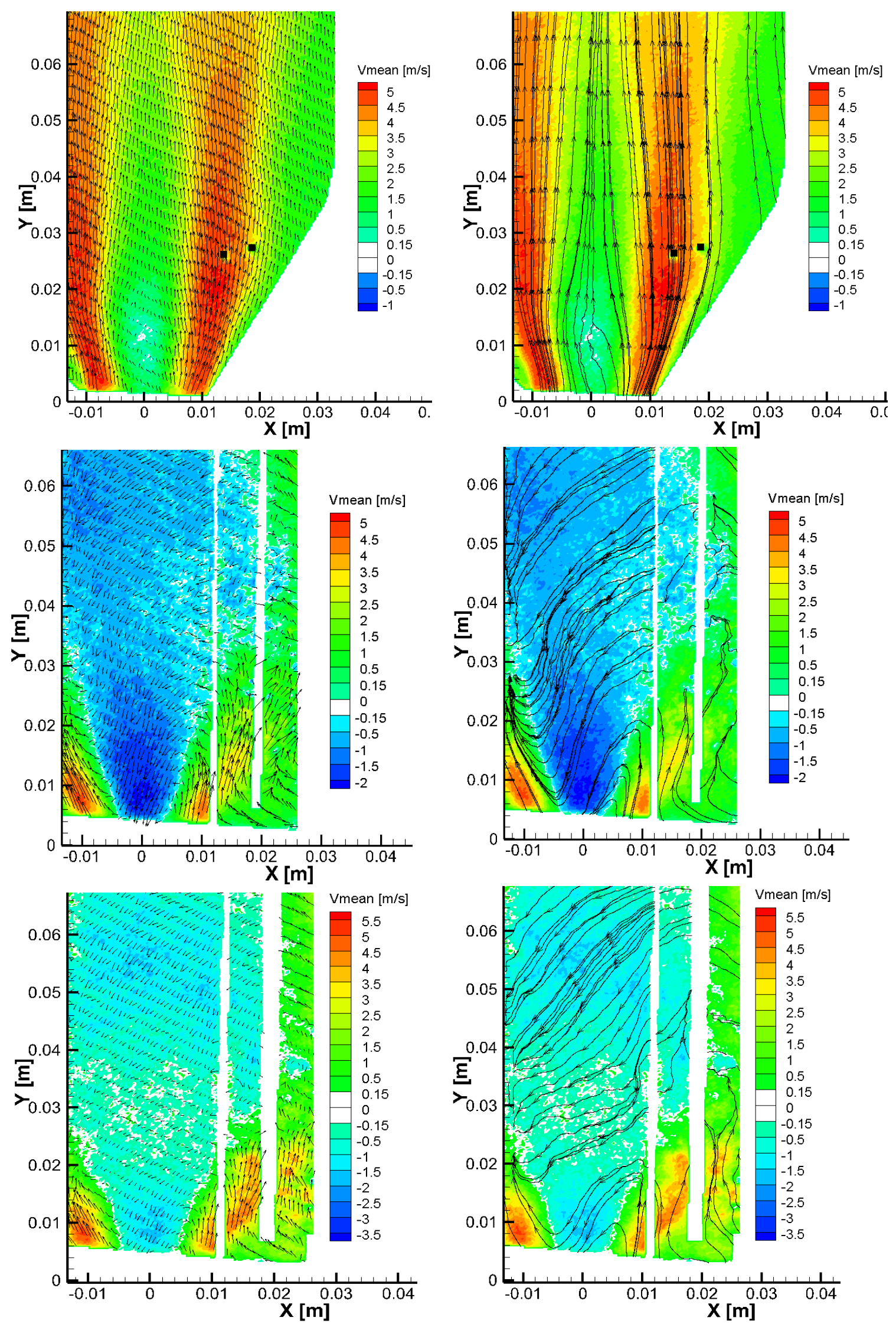

Figure 8. Velocity vectors and streamlines for unconfined case 4 (top), confined case 5 (middle), and confined increased Reynolds number case 6 (bottom) 

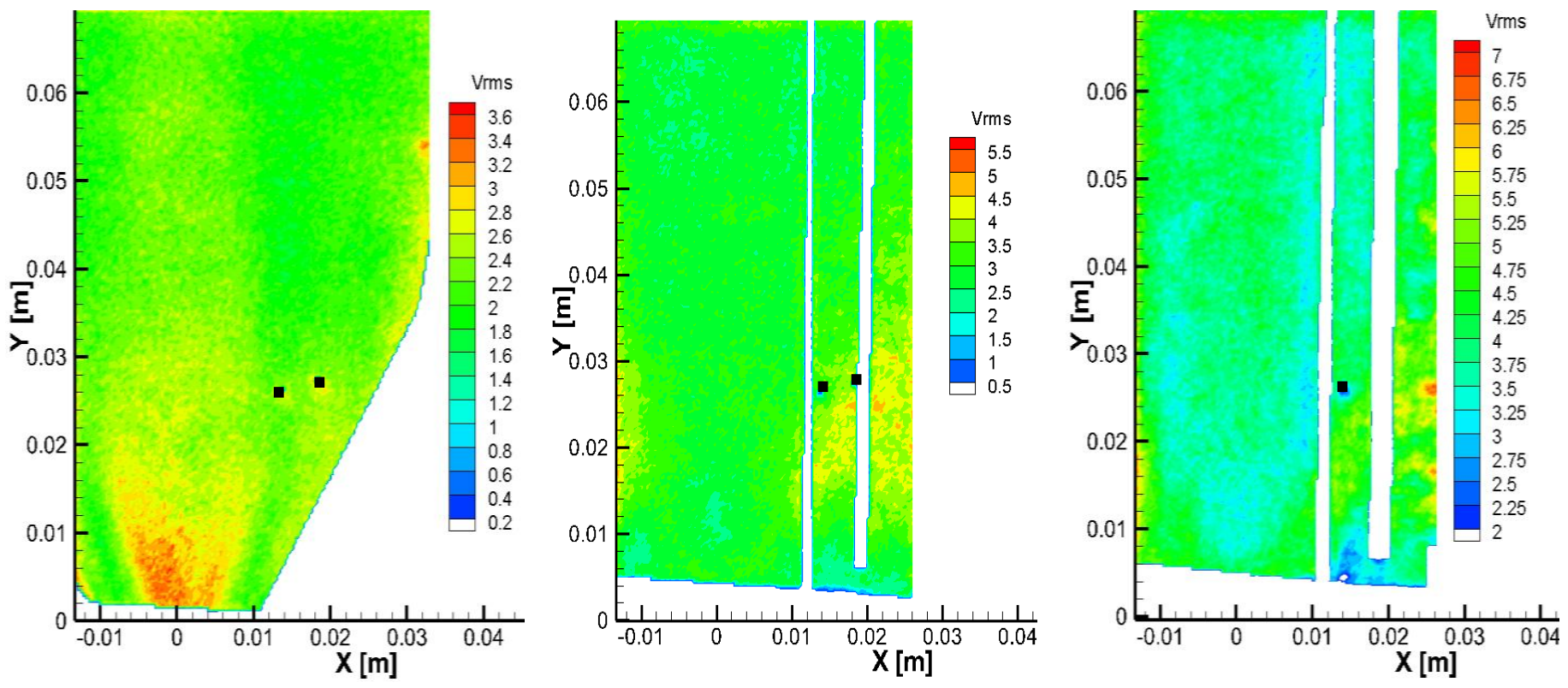

Figure 9. Fluctuating velocity for unconfined case 4 (left), confined case 5 (middle), and confined increased Reynolds number case 6 (right) 

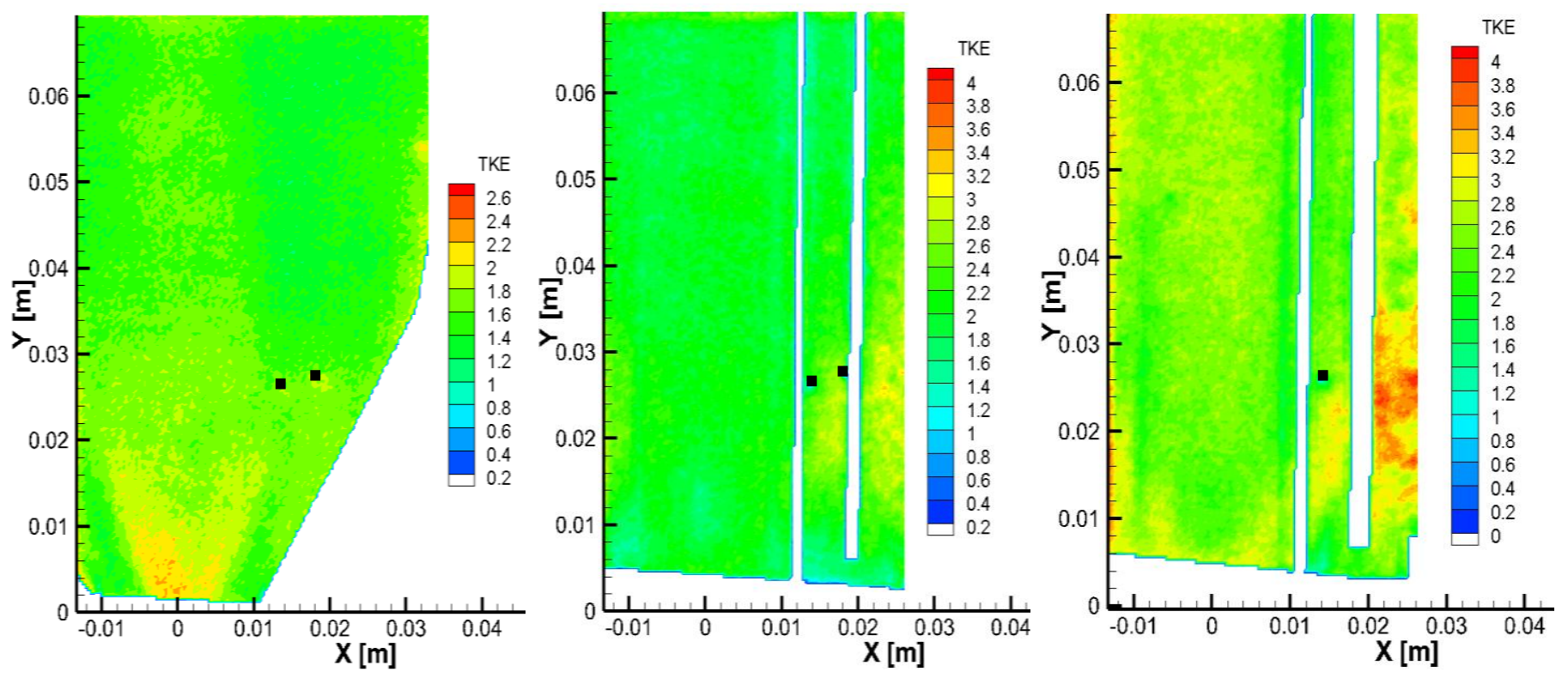

Figure 10. Turbulent kinetic energy $(\mathrm{m} / \mathrm{s})$ for unconfined case 4 (left), confined case 5 (middle), and confined increased Revnolds number case 6 (right) 
Table 1. PIV Parameters

\begin{tabular}{|c|c|}
\hline Seeding Particle & Alumina \\
\hline Size & $2 \mu \mathrm{m}$ \\
\hline Rate & $5 \mathrm{~Hz}$ \\
\hline No. of Image Pairs & 300 \\
\hline Laser Sheet thickness & $\sim 1 \mathrm{~mm}$ \\
\hline Pulse Separation & $60 \mu \mathrm{s}$ \\
\hline Interrogation Window Size & $48 \times 48$ down to $12 \times 12$ pixels \\
\hline Camera Resolution & $1360 \times 1036$ pixels \\
\hline Velocity Field Spatial Resolution & $0.7 \times 0.7 \mathrm{~mm}$ \\
\hline Lens Focal Length & $60 \mathrm{~mm}$ \\
\hline f-stop setting & 2.8 \\
\hline Seeding air Percentage & $\sim 10 \%$ \\
\hline
\end{tabular}


Table 2. Experimental parameters

\begin{tabular}{|l|c|c|c|c|c|c|}
\hline & Reacting & Confined & $\begin{array}{c}\text { Equivalence } \\
\text { Ratio }\end{array}$ & Reynolds' Number & \multicolumn{2}{|c|}{ Flowrates $[1 / \mathbf{m i n}]$} \\
\cline { 5 - 7 } & & & Air & $\mathbf{C H}_{4}$ \\
\hline 1 & No & No & - & $\sim \mathbf{4 0 8 0}$ & $\mathbf{6 3 . 9}$ & - \\
\hline 2 & No & Yes & - & $\sim 4080$ & $\mathbf{6 3 . 9}$ & - \\
\hline 3 & No & Yes & - & $\sim \mathbf{6 0 8 0}$ & $\mathbf{9 5 . 2}$ & - \\
\hline 4 & Yes & No & $\mathbf{0 . 9}$ & $\sim \mathbf{4 4 5 0}$ & $\mathbf{6 3 . 9}$ & $\mathbf{6}$ \\
\hline 5 & Yes & Yes & $\mathbf{0 . 9}$ & $\sim \mathbf{4 4 5 0}$ & $\mathbf{6 3 . 9}$ & $\mathbf{6}$ \\
\hline 6 & Yes & Yes & $\mathbf{0 . 6}$ & $\sim \mathbf{6 4 5 0}$ & $\mathbf{9 5 . 2}$ & $\mathbf{6}$ \\
\hline
\end{tabular}

[21] 